Brief Report

\title{
Utility of Direct Fast Scarlet Staining in the Histopathological Diagnosis of Eosinophilic Esophagitis: A Short Report
}

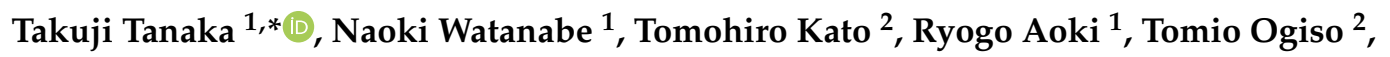 \\ Akihiko Sugiyama ${ }^{2}$ and Eiichi Tomita ${ }^{2}$ (D) \\ 1 Department of Diagnostic Pathology \& Research Center of Diagnostic Pathology, Gifu Municipal Hospital, \\ 7-1 Kashima-cho, Gifu City 500-8513, Japan; naoki@watanabe.name (N.W.); ryogo0718@yahoo.co.jp (R.A.) \\ 2 Department of Internal Medicine, Gifu Municipal Hospital, Gifu City 500-8513, Japan; \\ gif235@gifu-u.ac.jp (T.K.); tommy4000jp@yahoo.co.jp (T.O.); billsugiyama1025@yahoo.co.jp (A.S.); \\ etomita_jp@yahoo.co.jp (E.T.) \\ * Correspondence: takutt@gmhosp.gifu.gifu.jp
}

Received: 7 October 2020; Accepted: 29 October 2020; Published: 9 November 2020 updates

\begin{abstract}
Eosinophilic esophagitis (EoE), an atopic disease of the esophagus, has become increasingly recognized over the last 15 years. The epidemiology of EoE has now been reported from many countries around the world. While the clinical diagnosis of this disease depends on the patient's clinical manifestations, the final diagnosis should be made based on the histopathological examination of esophageal mucosal biopsies. In the diagnosis of EoE, to facilitate the appropriate treatment of patients, it is extremely important to precisely recognize the presence of eosinophils in biopsy specimens of the esophageal mucosa. If eosinophils are present, EoE patients should be referred to an allergist for appropriate management with dietary modification, pharmacological agents (including corticosteroids), and/or mechanical dilation of the esophagus. We herein present and recommend the use of direct fast scarlet staining for the easy and precise recognition of eosinophils in biopsy specimens of the esophageal mucosa, a technique that has been routinely used in our laboratory.
\end{abstract}

Keywords: eosinophilic esophagitis; eosinophils; esophageal mucosal biopsy; direct fast scarlet staining

\section{Introduction}

Eosinophilic esophagitis (EoE) is a chronic and immune-mediated esophageal disease caused by a large number of eosinophils infiltrating the epithelium of the esophageal mucosa [1]. Patients with EoE present various symptoms, which differ according to age. These include dysphagia, dysfunctional feeding, food impaction, chest pain, gastroesophageal reflux disease (GERD)-like symptoms, abdominal pain, vomiting, and anorexia [1]. Landres et al. [2] first reported EoE in a patient with vigorous achalasia, which was considered a variant of eosinophilic gastroenteritis. Forget et al. [3] followed this by reporting an infant case of EoE. Lee [4] then reported young patients (average age of 14.6 years) with marked infiltration of the esophagus by eosinophils. In 1993, EoE was defined as a distinct clinicopathological disease entity [5]. Since then, case reports and small series of affected patients have increasingly appeared in the literature. Consensus recommendations on the diagnosis were documented for the first time in 2007, and updated in 2011 and 2017 [1,6,7]. All guidelines and/or recommendations cite a peak eosinophil count of $\geq 15$ eosinophils in at least one high-power field (HPF) in a biopsy specimen from at least one site among the distal, mid, and proximal portions of the esophagus as the pathologic criterion for the diagnosis of EoE. However, we have experienced cases in which it was difficult to identify eosinophil(s) infiltrating the esophageal mucosa on histological specimens stained with hematoxylin and eosin (H\&E), specifically when hemorrhage 
and/or congestion were found in the mucosa. To fully understand EoE, improvements in diagnostic techniques are essential.

Direct fast scarlet 4BS (DFS) is commonly used for staining amyloid deposited in tissues [8]. Two other staining methods, Congo red staining [9] and Dylon staining [10], which are used for the detection of amyloid, are reported to be useful for staining eosinophilic granules in tissue sections. In addition, several reports $[11,12]$ have described that DFS staining can visualize cytoplasmic granules of eosinophils.

In this short report, we introduced the utility of direct fast scarlet staining for identifying eosinophilic granules in tissues and for the diagnosis of EoE. This staining technique was originally used for detecting amyloid deposits in tissues.

\section{Results}

The present study included a total of 46 cases in which EoE was clinically diagnosed based on endoscopic findings, and then processed for histopathological examination. The biopsy specimens obtained during endoscopic examination were processed for routine histopathological examination. After, two serial sections were made and stained with H\&E and DFS, respectively. The number of eosinophils per HPF was counted on both sections. Our results are summarized in Table 1. It was difficult for us to identify eosinophils on biopsy specimens stained with H\&E, especially in cases where hemorrhage and congestion were present in the esophageal squamous cell epithelium (Figure 1a,c) and in which degranulation of eosinophils occurred (Figure 1a). However, we clearly detected eosinophils in the esophageal squamous cell epithelium with DFS staining (Figure 1b,d). On the H\&E-stained section (Figure 1a,c,e,g), 18 (39.1\%) of 46 cases had more than 15 eosinophils/HPF in the esophageal epithelium. On the other hand, we found that 27 (58.7\%) of 46 cases had more than 15 eosinophils/HPF in the esophageal mucosa stained with DFS (Figure 1b,d,f,h). On the DFS-stained sections alone, we detected $\geq 15$ eosinophils/HPF in a total of nine cases (case nos. 3, 8, 19, 27, 29, 32, 33, 34, and 46), in which $<15$ eosinophils/HPF were counted on the H\&E-stained section (Table 1). Finally, 27 (58.7\%) of 46 cases were histopathologically diagnosed as EoE, confirming the clinical diagnosis (Table 1). Fisher's exact probability test revealed a statistically significant difference $(p=0.0018)$ between H\&E staining (18/27 cases) and DFS staining (27/27 cases) for diagnosis of EoE by identification of eosinophils infiltrated in the esophageal epithelium. In cases 20, 21, and 28, a number of eosinophils were clearly observed to have infiltrated the duodenal mucosa (Figure 1i,j) or gastric mucosa (Figure 2b), suggesting that the patients had eosinophilic enteritis or eosinophilic gastritis [13]. All patients histopathologically diagnosed with EoE received a proton pump inhibitor or corticoseroid and were confirmed for histological remission ( $\leq 5$ eosinophils/HPF).

Table 1. The histopathological diagnosis on H\&E- and DFS-stained sections obtained from esophageal biopsies of clinically/endoscopically diagnosed EoE patients.

\begin{tabular}{cccccc}
\hline Case No. & Sex & Age & \multicolumn{2}{c}{ No. of Eosinophils/HPF } & Final Diagnosis \\
\cline { 5 - 6 } & (Female/Male) & (Years) & $\begin{array}{c}\text { H\&E-Stained } \\
\text { Section }\end{array}$ & $\begin{array}{c}\text { DFS-Stained } \\
\text { Section }\end{array}$ & Glycogenic acanthosis \\
\hline 1 & Female & 55 & 3 & 0 & GERD \\
\hline 2 & Female & 81 & 0 & 4 & EoE \\
\hline 3 & Male & 52 & 10 & 42 & Esophageal ulcer \\
\hline 4 & Female & 26 & 5 & 8 & GERD \\
\hline 6 & Male & 85 & 0 & 0 & GERD \\
\hline 7 & Male & 19 & 4 & 1 & No esophageal lesion \\
\hline 8 & Female & 18 & 0 & 0 & EoE \\
\hline
\end{tabular}


Table 1. Cont.

\begin{tabular}{|c|c|c|c|c|c|}
\hline \multirow[b]{2}{*}{ Case No. } & \multirow{2}{*}{$\begin{array}{c}\text { Sex } \\
\text { (Female/Male) }\end{array}$} & \multirow{2}{*}{$\begin{array}{l}\text { Age } \\
\text { (Years) }\end{array}$} & \multicolumn{2}{|c|}{ No. of Eosinophils/HPF } & \multirow[b]{2}{*}{ Final Diagnosis } \\
\hline & & & $\begin{array}{l}\text { H\&E-Stained } \\
\text { Section }\end{array}$ & $\begin{array}{l}\text { DFS-Stained } \\
\text { Section }\end{array}$ & \\
\hline 9 & Male & 24 & 15 & 23 & EoE \\
\hline 10 & Male & 63 & 5 & 8 & GERD \\
\hline 11 & Male & 49 & 3 & 8 & GERD \\
\hline 12 & Male & 13 & 1 & 5 & GERD \\
\hline 13 & Male & 58 & 15 & 24 & EoE \\
\hline 14 & Male & 12 & 0 & 3 & Hiatal herniation \\
\hline 15 & Male & 24 & 62 & 133 & $\mathrm{EoE}$ \\
\hline 16 & Male & 73 & 10 & 8 & GERD \\
\hline 17 & Female & 66 & 3 & 0 & GERD \\
\hline 18 & Male & 24 & 2 & 6 & GERD \\
\hline 19 & Male & 49 & 5 & 30 & EoE \\
\hline 20 & Female & 49 & 28 & 49 & $\mathrm{EoE}^{*}$ \\
\hline 21 & Female & 53 & 16 & 55 & $\mathrm{EoE}^{*}$ \\
\hline 22 & Female & 50 & 52 & 84 & $\mathrm{EoE}$ \\
\hline 23 & Female & 49 & 30 & 34 & EoE \\
\hline 24 & Male & 22 & 25 & 120 & EoE \\
\hline 25 & Male & 57 & 37 & 58 & $\mathrm{EoE}$ \\
\hline 26 & Female & 50 & 11 & 2 & GERD \\
\hline 27 & Male & 25 & 6 & 15 & EoE \\
\hline 28 & Female & 60 & 15 & 24 & $\mathrm{EoE}^{*}$ \\
\hline 29 & Male & 43 & 13 & 45 & EoE \\
\hline 30 & Male & 35 & 22 & 21 & $\mathrm{EoE}$ \\
\hline 31 & Female & 48 & 25 & 48 & $\mathrm{EoE}$ \\
\hline 32 & Male & 80 & 3 & 27 & $\mathrm{EoE}$ \\
\hline 33 & Female & 49 & 12 & 23 & EoE \\
\hline 34 & Female & 50 & 13 & 26 & $\mathrm{EoE}$ \\
\hline 35 & Female & 72 & 5 & 0 & GERD \\
\hline 36 & Male & 25 & 98 & 183 & $\mathrm{EoE}$ \\
\hline 37 & Female & 18 & 55 & 143 & $\mathrm{EoE}$ \\
\hline 38 & Male & 49 & 3 & 0 & Barrett's esophagus \\
\hline 39 & Male & 55 & 0 & 0 & GERD \\
\hline 40 & Male & 14 & 30 & 20 & $\mathrm{EoE}$ \\
\hline 41 & Female & 51 & 10 & 1 & GERD \\
\hline 42 & Male & 15 & 27 & 32 & $\mathrm{EoE}$ \\
\hline 43 & Male & 14 & 62 & 96 & EoE \\
\hline 44 & Female & 46 & 3 & 1 & Glycogenic acanthosis \\
\hline 45 & Female & 51 & 15 & 31 & $\mathrm{EoE}$ \\
\hline 46 & Female & 51 & 14 & 32 & $\mathrm{EoE}$ \\
\hline
\end{tabular}

* A number of eosinophils are present in the gastric and/or duodenal mucosa. 

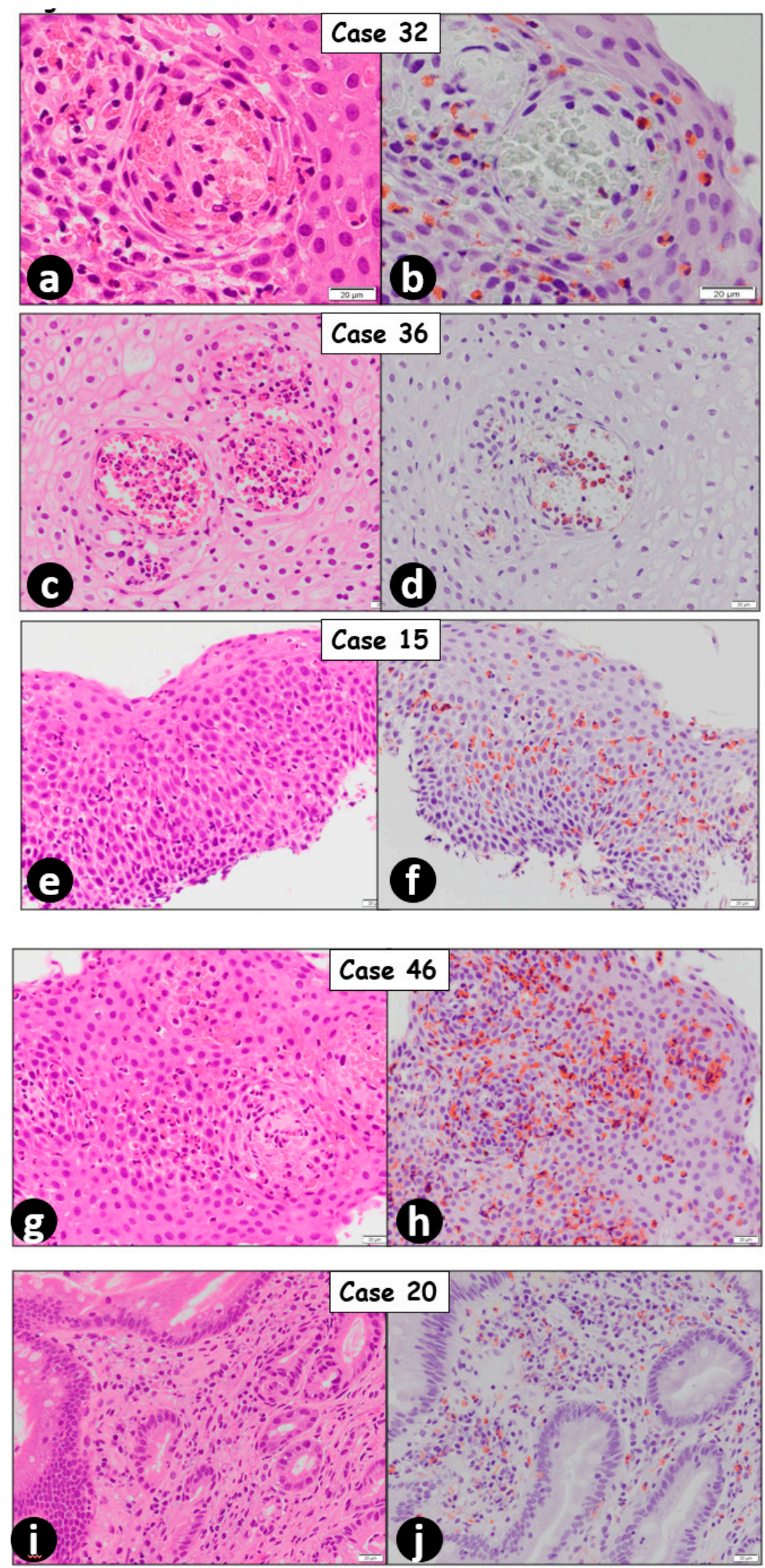

Figure 1. Two serial sections stained with H\&E (a,c,e,g) and DFS (b,d,f,h) from esophageal biopsy specimens in case nos. 32, 36, 15, and 46. Eosinophils with bright orange-colored granules are noted in the squamous epithelium (b,d,f,h). On the duodenal biopsy specimen stained with H\&E (i) and DFS (j) from case no. 20, eosinophilic cytoplasmic granules are clearly seen in bright orange by DFS staining (j). Note: small and bright orange-colored granules in the cytoplasm of the esophageal squamous epithelium are degranulation of eosinophils $(\mathbf{b}, \mathbf{d}, \mathbf{f}, \mathbf{h}, \mathbf{j})$. H\&E and DFS staining, bar $20 \mathrm{~m}$. 


(1) Preparation of DFS solution:
DFS 4BS $0.1 \mathrm{~g}$ is dissolved in $50 \mathrm{ml}$ of $50 \%$
isopropyl alcohol, and then add $0.4 \mathrm{~g}$ of sodium
sulfate (anhydrate). The solution is stirred
using a stirrer for $10 \mathrm{~min}$ and then filtered just
before use.
(2) Staining procedure:
1. A section is deparaffinized and rehydrated
2. Wash in tap water and place in distilled
water
3. Stain with a DFS solution for 10 min
4. Wash in tap water
5. Wash in distilled water
6. Deep in Mayer's hematoxylin for 3 min
7. Differentiate in diluted ammonia water ()
for a few seconds
8. Wash in tap water
9. Dehydration, clear, and mount

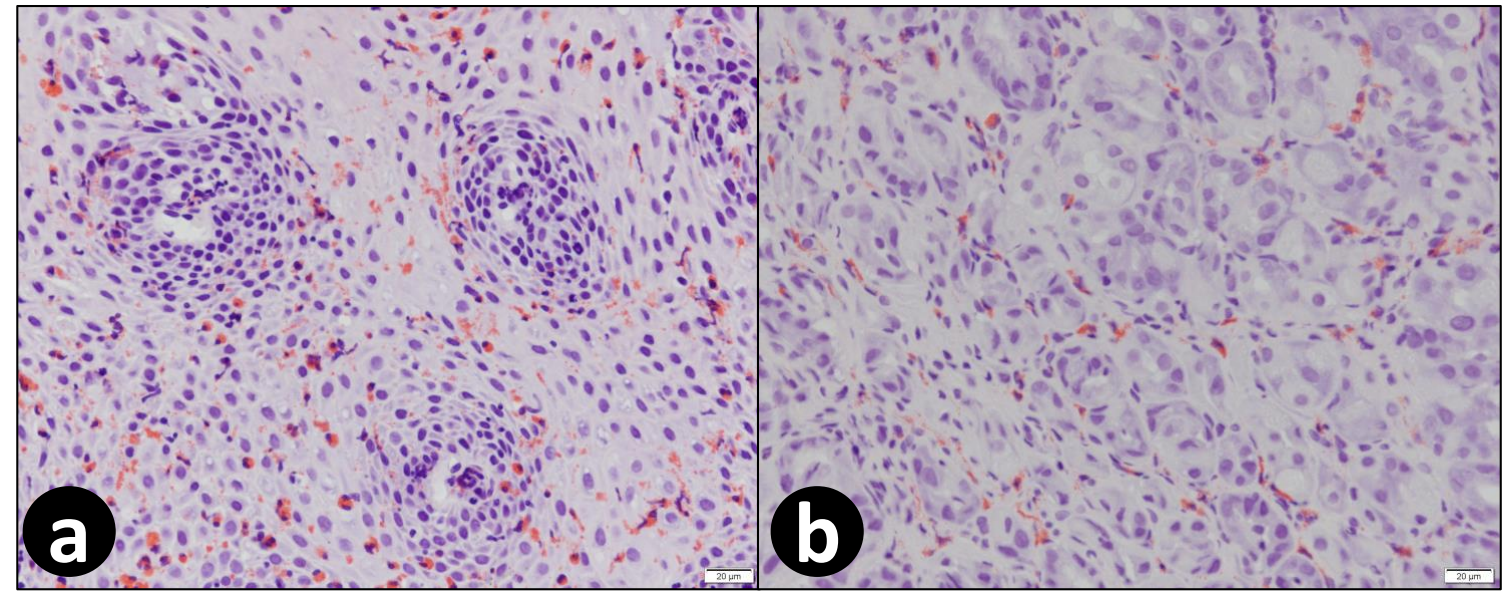

Figure 2. The preparation of the DFS solution and the DFS staining procedure. Note: the bright orange-colored granules of eosinophils are ones that infiltrated (a) the esophageal squamous epithelium and (b) gastric mucosa stained with DFS. DFS staining, bar $20 \mathrm{~m}$.

\section{Discussion}

In the current study, we detected eosinophils on DFS-stained specimens more easily in comparison to H\&E-stained sections. The preparation of the DFS staining solution and the staining procedure are simple, practical, and can be routinely applied in a histopathology laboratory to identify cytoplasmic granules of eosinophils. 
In the assessment of biopsy tissues for EoE, well-oriented biopsy specimens of full epithelial thickness of the esophagus are necessary. Quite often, biopsy samples are taken with small pinch forceps, which results in a small, superficial specimen that is difficult to orient. If endoscopy is being performed to obtain a pathological diagnosis, an appropriate endoscope with forceps that are capable of grasping large specimens should be used. It is important to avoid the use of picric acid-containing dyes and fixatives, for example, Bouin's solution, because this interferes with the staining of the eosinophil granules, finally resulting in failure to recognize the granules.

The increasing number of EoE cases throughout the world, especially in Western countries [14], and several risk factors, such as sex (male predominant), race (Caucasian), and other allergic conditions (asthma, seasonal rhinitis, and atopic dermatitis), are known to be associated with the development of EoE [15]. However, in Japan, EoE is a rarer disease in comparison to Western countries [16]. The precise reason for this is not known, although a recent higher awareness of EoE among Japanese endoscopic physicians has resulted in an increased prevalence of EoE [17], which is reported to range between $0.02 \%$ and $0.4 \%$ [17-20]; this prevalence is still lower than that in Western countries $(0.057 \%$ [21]).

EoE is defined as a clinicopathological disease characterized by $\geq 15$ eosinophils/HPF in one or more esophageal mucosal biopsy specimens without pathologic findings of GERD [22,23]. However, the number of eosinophilic alone does not differentiate EoE from GERD [24]. In our study, GERD was the most important differential diagnosis of EoE, as listed in Table 1. The integration of histopathological findings with clinical data and endoscopic findings is thus required for accurate medical management [24].

All guidelines or recommendations published from 2007 cited a peak eosinophil count ( $\geq 15$ eosinophils) in at least one HPF in an esophageal biopsy specimen from at least one site in the esophagus (distal, mid, or proximal) as the pathological criterion for the final diagnosis $[1,6,7,23]$. However, Adachi et al. [18] recently reported that lower sites of the esophagus are the most suitable for biopsies for the detection of EoE and the presence of exudate in EoE can be suspected based on endoscopic findings. In cases of GERD in which eosinophils are also present in the esophageal epithelium [24], alterations may have a patchy distribution; thus, multiple biopsies are required and recommended.

\section{Materials and Methods}

We conducted a histopathological analysis of a total of 46 cases of clinically diagnosed EoE. All patients visited our hospital from April 2017 to September 2020. According to the diagnostic algorithm for EoE in our hospital, when the patients have certain symptoms that are suggestive of EoE, an upper gastrointestinal endoscopic examination using Olympus GIF-H260 (Olympus Co., Tokyo, Japan) is performed. Upper gastrointestinal endoscopic findings that are suggestive of EoE include linear furrows, rings, whitish exudate or plaque, edema, strictures, or a fragile mucosa [25]. In this study, a total of 46 patients (females, $n=19$; males, $n=27$, Table 1 ) were clinically diagnosed with EoE based on the endoscopic findings, which included linear erosion/ulcer, linear or circular edematous mucosa, mucosal scarring, and localized white spots. During the endoscopic examination, biopsy specimens were obtained from the esophageal lesion(s). The biopsied tissues were fixed in $10 \%$ neutral buffered formalin for at least $3 \mathrm{~h}$, processed routinely for the histopathological examination, and then two serial sections (each 3-4 $\mathrm{m}$ in thickness) were made for each biopsy specimen. One section was stained with H\&E for a histopathological analysis, including the counting of eosinophils present in the esophageal mucosa. The other section was stained with DFS (Muto Pure Chemicals Co., Ltd., Tokyo, Japan) to detect cytoplasmic granules of eosinophils. The preparation of the DFS solution and the procedure for DFS staining using benzo fast scarlet $4 \mathrm{BS}\left(\mathrm{C}_{35} \mathrm{H}_{25} \mathrm{~N}_{7} \mathrm{Na}_{2} \mathrm{O}_{10} \mathrm{~S}_{2}, \mathrm{MW}\right.$ 813.74) [12], which was modified from the Yanagihara's method of Dylon staining using Pagoda Red to detect amyloid deposition [10,26], are shown in Figure 2. The DFS solution could clearly and specifically stain cytoplasmic granules of eosinophils, yielding a bright orange color (Figure 2a,b). 


\section{Conclusions}

We tried to use DFS staining to identify eosinophils that infiltrated the esophageal squamous epithelium of patients who were clinically diagnosed with EoE. DFS staining enabled us to clearly observe bright orange-colored granules in the cytoplasm of eosinophils. Since the staining method is simple and practical, it can be routinely used in the histopathological diagnosis of EoE. Furthermore, it could easily detect eosinophils in tissues other than esophageal tissue.

Author Contributions: Conceptualization, T.T., T.K., E.T.; methodology, N.W., R.A., T.O., A.S.; writing the original draft, T.T.; writing, reviewing, and editing, T.T., N.W., T.K., R.A., T.O., A.S., E.T. All authors have read and agreed to the published version of the manuscript.

Funding: This research received no external funding.

Acknowledgments: The authors thank all of the staff for preparing the pathological specimens.

Conflicts of Interest: The authors declare no conflict of interest in association with the present study.

\section{References}

1. Liacouras, C.A.; Furuta, G.T.; Hirano, I.; Atkins, D.; Attwood, S.E.; Bonis, P.A.; Burks, A.W.; Chehade, M.; Collins, M.H.; Dellon, E.S.; et al. Eosinophilic esophagitis: Updated consensus recommendations for children and adults. J. Allergy Clin. Immunol 2011, 128, 3-20.e6. [CrossRef] [PubMed]

2. Landres, R.T.; Kuster, G.G.; Strum, W.B. Eosinophilic esophagitis in a patient with vigorous achalasia. Gastroenterology 1978, 74, 1298-1301. [CrossRef]

3. Forget, P.; Eggermont, E.; Marchal, G.; Geboes, K.; Jaeken, J.; Melchior, S. Eosinophilic infiltration of the oesophagus in an infant. Acta Paediatr. Belg. 1978, 31, 91-93. [PubMed]

4. Lee, R.G. Marked eosinophilia in esophageal mucosal biopsies. Am. J. Surg. Pathol. 1985, 9, 475-479. [CrossRef] [PubMed]

5. Attwood, S.E.; Smyrk, T.C.; Demeester, T.R.; Jones, J.B. Esophageal eosinophilia with dysphagia. A distinct clinicopathologic syndrome. Dig. Dis. Sci. 1993, 38, 109-116. [CrossRef]

6. Furuta, G.T.; Liacouras, C.A.; Collins, M.H.; Gupta, S.K.; Justinich, C.; Putnam, P.E.; Bonis, P.; Hassall, E.; Straumann, A.; Rothenberg, M.E.; et al. Eosinophilic esophagitis in children and adults: A systematic review and consensus recommendations for diagnosis and treatment. Gastroenterology 2007, 133, 1342-1363. [CrossRef]

7. Lucendo, A.J.; Molina-Infante, J.; Arias, A.; von Arnim, U.; Bredenoord, A.J.; Bussmann, C.; Amil Dias, J.; Bove, M.; Gonzalez-Cervera, J.; Larsson, H.; et al. Guidelines on eosinophilic esophagitis: Evidence-based statements and recommendations for diagnosis and management in children and adults. United Eur. Gastroenterol. J. 2017, 5, 335-358. [CrossRef] [PubMed]

8. Hirano, T.; Numakura, T.; Moriyama, H.; Saito, R.; Shishikura, Y.; Shiihara, J.; Sugiura, H.; Ichinose, M. The first case of multiple pulmonary granulomas with amyloid deposition in a dental technician; a rare manifestation as an occupational lung disease. BMC Pulm. Med. 2018, 18, 77. [CrossRef]

9. Grouls, V.; Helpap, B. Selective staining of eosinophils and their immature precursors in tissue sections and autoradiographs with Congo red. Stain Technol. 1981, 56, 323-325. [CrossRef]

10. Yanagihara, M.; Mehregan, A.H.; Mehregan, D.R. Staining of amyloid with cotton dyes. Arch. Dermatol. 1984, 120, 1184-1185. [CrossRef]

11. Madokoro, Y.; Kato, H.; Yuasa, H.; Ootaka, N.; Mori, Y.; Mitake, S. A case of eosinophilic myositis presenting with myocarditis and cardiac embolism. Rinsho Shinkeigaku 2015, 55, 45-48. [CrossRef]

12. Saga, S. Staining of granules of eosinophils by DFS. Mod. Med. Lab. (Kensa-to-Gojyutsu) 2019, 47, 499-502. (In Japanese)

13. Collins, M.H.; Capocelli, K.; Yang, G.Y. Eosinophilic Gastrointestinal Disorders Pathology. Front. Med. 2017, 4, 261. [CrossRef]

14. Prasad, G.A.; Alexander, J.A.; Schleck, C.D.; Zinsmeister, A.R.; Smyrk, T.C.; Elias, R.M.; Locke, G.R., 3rd; Talley, N.J. Epidemiology of eosinophilic esophagitis over three decades in Olmsted County, Minnesota. Clin. Gastroenterol. Hepatol. 2009, 7, 1055-1061. [CrossRef] [PubMed] 
15. Carr, S.; Chan, E.S.; Watson, W. Eosinophilic esophagitis. Allergy Asthma Clin. Immunol. 2018, $14,58$. [CrossRef] [PubMed]

16. Ishimura, N.; Kinoshita, Y. Eosinophilic esophagitis in Japan: Focus on response to acid suppressive therapy. J. Gastroenterol. Hepatol. 2018, 33, 1016-1022. [CrossRef] [PubMed]

17. Imamura, K.; Haruma, K.; Matsumoto, H.; Maruyama, Y.; Ayaki, M.; Tazaki, S.; Hisamoto, N.; Manabe, N.; Kamada, T.; Kawamoto, H. Clinical and endoscopic characteristics of eosinophilic esophagitis in Japan: A case-control study. Asia Pac. Allergy 2020, 10, e16. [CrossRef]

18. Adachi, K.; Mishiro, T.; Tanaka, S.; Kinoshita, Y. Suitable biopsy site for detection of esophageal eosinophilia in eosinophilic esophagitis suspected cases. Dig. Endosc. 2016, 28, 139-144. [CrossRef]

19. Fujishiro, H.; Amano, Y.; Kushiyama, Y.; Ishihara, S.; Kinoshita, Y. Eosinophilic esophagitis investigated by upper gastrointestinal endoscopy in Japanese patients. J. Gastroenterol. 2011, 46, 1142-1144. [CrossRef]

20. Sato, H.; Honma, T.; Nozawa, Y.; Owaki, T.; Imai, M.; Sano, T.; Iwanaga, A.; Seki, K.; Ishikawa, T.; Yoshida, T.; et al. Eosinophilic esophagitis in Japanese patients: A mild and slow-progressing disorder. PLoS ONE 2018, 13, e0206621. [CrossRef]

21. Moawad, F.J. Eosinophilic Esophagitis: Incidence and Prevalence. Gastrointest. Endosc. Clin. N. Am. 2018, 28, 15-25. [CrossRef]

22. Chen, J.W.; Kao, J.Y. Eosinophilic esophagitis: Update on management and controversies. BMJ 2017, 359, j4482. [CrossRef]

23. Dellon, E.S.; Gonsalves, N.; Hirano, I.; Furuta, G.T.; Liacouras, C.A.; Katzka, D.A.; American College of Gastroenterology. ACG clinical guideline: Evidenced based approach to the diagnosis and management of esophageal eosinophilia and eosinophilic esophagitis (EoE). Am. J. Gastroenterol. 2013, 108, 679-692, quiz 693. [CrossRef]

24. Genevay, M.; Rubbia-Brandt, L.; Rougemont, A.L. Do eosinophil numbers differentiate eosinophilic esophagitis from gastroesophageal reflux disease? Arch. Pathol. Lab. Med. 2010, 134, 815-825. [PubMed]

25. Ishimura, N.; Okimoto, E.; Shibagaki, K.; Nagano, N.; Ishihara, S. Similarity and difference in the characteristics of eosinophilic esophagitis between Western countries and Japan. Dig. Endosc. 2020. [CrossRef]

26. Horiguchi, Y.; Takahashi, C.; Imamura, S. A case of nodular cutaneous amyloidosis. Amyloid production by infiltrating plasma cells. Am. J. Dermatopathol. 1993, 15, 59-63. [CrossRef] [PubMed]

Publisher's Note: MDPI stays neutral with regard to jurisdictional claims in published maps and institutional affiliations.

(C) 2020 by the authors. Licensee MDPI, Basel, Switzerland. This article is an open access article distributed under the terms and conditions of the Creative Commons Attribution (CC BY) license (http://creativecommons.org/licenses/by/4.0/). 